Issued by Sandia National Laboratories, operated for the United States Department of Energy by Sandia Corporation.

NOTICE: This report was prepared as an account of work sponsored by an agency of the United States Government. Neither the United States Government, nor any agency thereof, nor any of their employees, nor any of their contractors, subcontractors, or their employees, make any warranty, express or implied, or assume any legal liability or responsibility for the accuracy, completeness, or usefulness of any information, apparatus, product, or process disclosed, or represent that its use would not infringe privately owned rights. Reference herein to any specific commercial product, process, or service by trade name, trademark, manufacturer, or otherwise, does not necessarily constitute or imply its endorsement, recommendation, or favoring by the United States Government, any agency thereof, or any of their contractors or subcontractors. The views and opinions expressed herein do not necessarily state or reflect those of the United States Government, any agency thereof, or any of their contractors.

Printed in the United States of America. This report has been reproduced directly from the best available copy.

Available to $\mathrm{DOE}$ and $\mathrm{DOE}$ contractors from Office of Scientific and Technical Information P.O. Box 62

Oak Ridge, TN 37831

Prices available from (703) 605-6000

Web site: http://www.ntis.gov/ordering.htm

Available to the public from

National Technical Information Service

U.S. Department of Commerce

5285 Port Royal Rd

Springfield, VA 22161

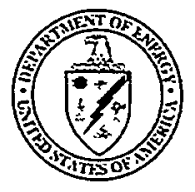




\section{DISCLAIMER}

Portions of this document may be illegible in electronic image products. Images are produced from the best available original document. 
SAND99-3098

Unlimited Release

Printed December 1999

\title{
Guidelines for Sandia ASCI Verification and Validation Plans - Content and Format:
}

\section{Version 1.0}

\author{
Timothy G. Trucano \\ Optimization and Uncertainty Estimation \\ Jaime L. Moya \\ Nuclear Weapons Program Support \\ Sandia National Laboratories \\ P. O. Box 5800 \\ Albuquerque, New Mexico 87185-0819
}

\begin{abstract}
This report summarizes general guidelines for the development of Verification and Validation (V\&V) plans for ASCI code projects at Sandia National Laboratories. The main content categories recommended by these guidelines for explicit treatment in Sandia $V \& V$ plans are (1) stockpile drivers influencing the code development project; (2) the key phenomena to be modeled by the individual code; (3) software verification strategy and test plan; and (4) code validation strategy and test plans. The authors of this document anticipate that the needed content of the V\&V plans for the Sandia ASCI codes will evolve as time passes. These needs will be reflected by future versions of this document.
\end{abstract}




\section{Table of Contents}

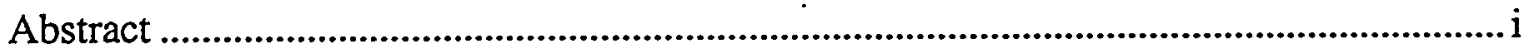

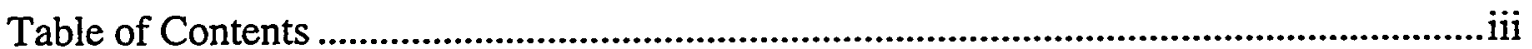

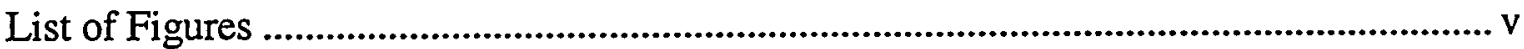

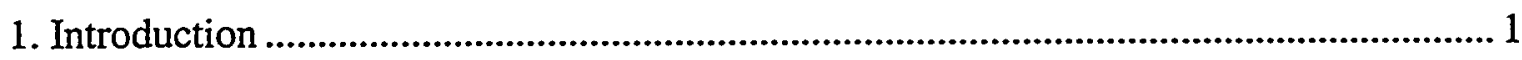

A. SNL's Verification \& Validation Program ........................................................... 1

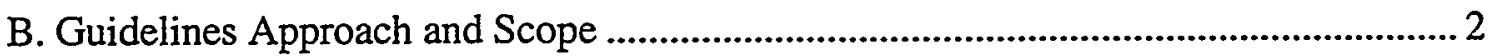

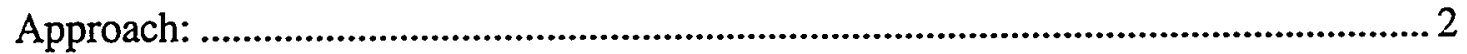

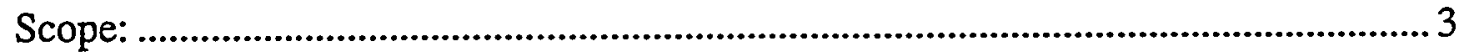

C. Sandia ASCI V\&V Programmatic Requirements ..................................................... 4

2. Stockpile Drivers, Needs, and Requirements.......................................................... 7

3. Phenomena Identification ànd Ranking Table ....................................................9

4. Software Verification Requirements and Verification Plan ...................................... 17

A. Defining Software Verification Requirements...................................................... 17

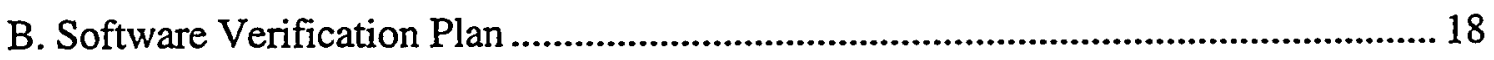

Software Development Process .......................................................................... 19

Software Engineering Techniques Applied in the Code Development ....................... 20

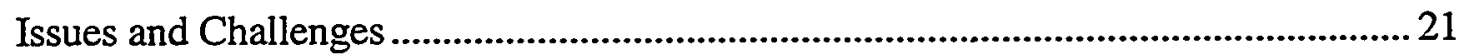

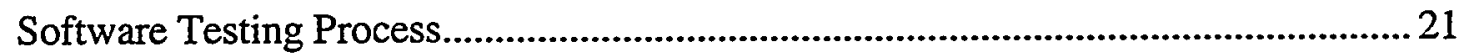

5. Software Validation Requirements and Validation Plan............................................. 23

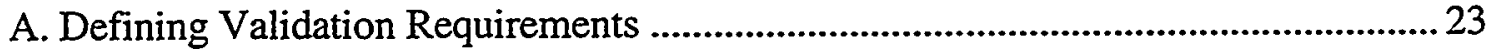

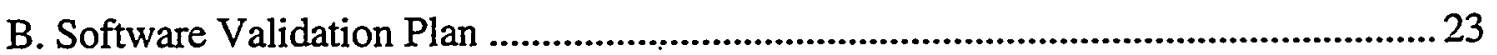

C. Protocols for Stockpile Computing ..................................................................... 25

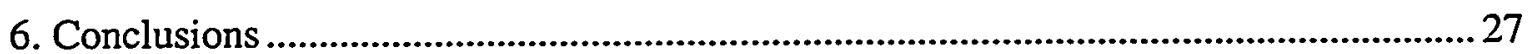

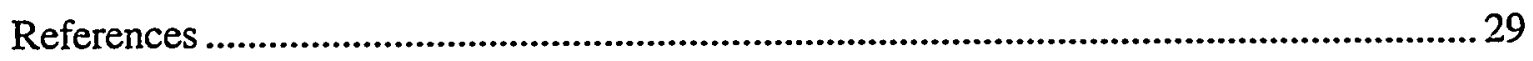

Appendix: Sandia ASCI V\&V Plan Table of Contents ............................................... 31

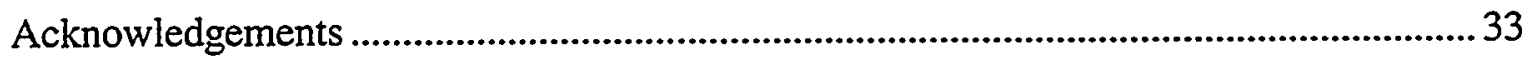


(Page Left Blank) 


\section{List of Figures}

Figure 1. Logic flow of requirements in the Sandia V\&V plans...................................... 8

Figure 2. A Phenomena Identification and Ranking Table (PIRT) - the simplest case... 10

Figure 3. A Phenomena Identification and Ranking Table (PIRT) - a slightly more complex case.

Figure 4. A Phenomena Identification and Ranking Table (PIRT) - a slightly more complex case with quantitative rankings.

Figure 5. A Phenomena Identification and Ranking Table (PIRT) - a slightly more complex case with more quantitative ranking approach and more than one way of using the code for the stockpile requirements.

Figure 6. A partial Phenomena Identification and Ranking Table (PIRT) for a complex stockpile application involving a NG neutron tube (Johannes, Private Communication).

Figure 7. The logic flow revisited: Flowchart of the needed content for Sandia ASCI Code V\&V plans. 
(Page Left Blank) 


\section{Introduction}

\section{A. SNL's Verification \& Validation Program}

The Department Of Energy's (DOE's) Accelerated Strategic Computing Initiative (ASCI) is designed to develop high performance computational tools and models to help manage the safety and reliability of the enduring nuclear stockpile. An important element of high consequence modeling and simulation $(M \& S)$ is a sound and viable verification and validation (V\&V) program - one that will substantively increase the credible predictive content of M\&S for Science Based Stockpile Stewardship while remaining within the constraints of available funding resources.

Verification and validation are defined in the DOE Defense Programs (DOE/DP) program plan for the Strategic Computing \& Simulation Validation \& Verification Program [1] as:

Verification - The process of determining that a computer simulation correctly represents the conceptual model and its solution.

Validation - The process of determining the degree to which a computer simulation is an accurate representation of the real world.

More informal definitions are also applicable in physical science based M\&S:

Verification - The process of determining that the equations are solved correctly.

Validation - The process of determining that the equations are correct.

These latter definitions recognize the basic focus of ASCI M\&S, which fundamentally deals with the numerical solution of equations. At the same time, these definitions emphasize that $V \& V$ is an open-ended process. This latter emphasis is particularly desirable to view $V \& V$ as a quality improvement process, which we intend to do in this document.

Sandia developed an ASCI V\&V Implementation Plan for Fiscal Year 1999 [2]. This Implementation Plan outlines three major V\&V activities for Sandia in FY 1999: (1) establish a process for developing and managing V\&V strategic plans; (2) prototype 
verification technologies and tools; and (3) qualify experimental data to support validation activities.

The purpose of the present document is to establish guidance for developing strategic V\&V plans for ASCI code projects at Sandia National Laboratories. Developing strategic $V \& V$ plans contributes to the achievement of both the $M \& S$ requirements and the programmatic needs of Sandia's National Security (NS) sector, as defined, for example, in the Stockpile Life Extension Plan (SLEP). The V\&V plans are expected to demonstrate and document how the quality and fidelity of the $M \& S$ capability will satisfy specific stockpile programmatic objectives. Each code development team, in partnership with their stockpile customers and designers, will create and maintain these plans throughout the life cycle of the code. Thus, V\&V activities are an integral part of the modeling and simulation lifecycle of the code. These $V \& V$ plans will be reviewed internally as well as externally to ensure that the V\&V plans have sufficient breadth and depth for fulfilling the stockpile M\&S requirements. The nuclear weapons design community at Sandia will be included in all of these coordination activities.

\section{B. Guidelines Approach and Scope}

\section{Approach:}

This document satisfies the requirement in Reference 2 to develop guidelines for Sandia $V \& V$ plans and reporting requirements. The main guidelines presented in this document are summarized as follows: Each code's strategic V\&V plan will contain separate sections on requirements, verification, and validation, respectively. Each plan will be written for a specific major stockpile driver. (If a given code has several stockpile drivers, then individual plans for each driver should be developed.)

The strategic V\&V plan will be written to demonstrate understanding of

1. The different levels of customers and their needs.

2. The different levels of requirements.

3. The drivers for these requirements (as defined in the SLEP, the Albuquerque Workload Planning Guide AWLPG 99-0, the weapons system groups work definitions, and the P\&PD).

4. The aspects of software quality assurance (SQA) and software engineering (SE) that influence the correctness of the software implementation. Finally, the anticipated testing approach for the code will be described. 
5. The code's anticipated testing approach will be described, both for verification and validation

6. The reliance upon existing or new experimental data of the validation testing approach for the code.

The main body of the present document is devoted to a more extensive discussion of these general guidelines.

\section{Scope:}

The scope of this guidance document covers the description and prioritization of the M\&S requirements that are driving the code development effort (hence our jargon "stockpile driver"). The plan's development will be based on the following strategic questions:

1. What is the current development status of the code or M\&S capability?

2. What are the gaps between a $M \& S$ capability's present status and what needs to be accomplished for its V\&V?

3. What are our $\mathrm{V} \& \mathrm{~V}$ planning assumptions and how do they correlate with the M\&S requirements?

4. What tactics need to be developed to address/overcome technical barriers?

5. What will be our key performance indicators?

6. How will project planning be handled?

To better understand the development of software requirements in the development of V\&V plans, we recommend Lee's Certainty in Stockpile Computing: Recommending a Verification and Validation Program for Scientific Software [3]. This document has a useful bibliography that supplements the one in the current document.

The following approach to building requirements into the development of individual code $\mathrm{V} \& \mathrm{~V}$ plans is the one we favor:

- Identifying programmatic (stockpile) drivers underlying the code project.

- Identifying the necessary phenomena and their required mathematics models. 
- Developing the software requirements (from the stockpile and phenomena requirements) and documenting the verification plan based on these requirements.

- Developing the validation requirements (from the stockpile and phenomena requirements), especially the requirements for validation data, and documenting the validation plan based on these requirements.

Each of these activities is discussed in greater detail below.

\section{Sandia ASCI V\&V Programmatic Requirements}

Besides the approach and scope, there are certain common elements to which each code $\mathrm{V} \& \mathrm{~V}$ plan should adhere in order to satisfy requirements of the Sandia ASCI V\&V program.

1. Uniformity:

All code $\mathrm{V} \& \mathrm{~V}$ plans should be structured similarly, as well as have the same common elements. This formal organization of the $V \& V$ plans promotes uniformity and provides easy access to information across the Sandia ASCI program. Uniformity also facilitates peer review of the plans and independent $\mathrm{V} \& \mathrm{~V}$ assessments.

2. Focus on stockpile drivers:

Stockpile drivers, defined by the AWLPG and determined through iteration with the Sandia weapon design community, should govern the V\&V program at Sandia and the associated processes. Each code's V\&V plan will be aimed at a specific stockpile driver, substantially limiting the scope of the requirements that are requested in the stockpile drivers and PIRT (see below) sections of this document. Additional stockpile drivers are included in additional plans, if necessary. The importance of connection and communication with the Sandia weapons program is clearly emphasized in this approach.

For example, let us consider two distinct stockpile drivers for the ALEGRA code project. First, there is the need to model the high explosive driven ferroelectric power supply of the neutron generator. This stockpile driver motivates the creation of one $\mathrm{V} \& \mathrm{~V}$ plan for the portion of ALEGRA aimed at this type of $M \& S$, called ALEGRA-EMMA. However, an additional stockpile driver placed on ALEGRA is to provide M\&S for the Sandia High Energy Density Physics (HEDP) program. This portion of ALEGRA is called ALEGRA-HEDP. Most of 
the stockpile requirements for the HEDP driver are disjoint from those for neutron generator power supplies. Hence, a second V\&V plan will be developed for ALEGRA-HEDP. There are other drivers for ALEGRA which likely will generate additional V\&V plans. Each separate plan aims at a substantial subset of the total M\&S phenomenology imbedded in ALEGRA.

3. Quality improvement:

Each code's associated $V \& V$ program is considered to be a quality improvement process for the code. The goal of the V\&V program is to improve the ability of the Sandia ASCI codes to achieve the objectives of their stockpile drivers.

4. Need for metrics:

Success of a code's V\&V program must be determined by developing and applying metrics. The metrics must be connected to the requirements and their priorities determined from the stockpile drivers.

5. Budget is a secondary issue:

Budget issues should not be presented as constraining factors in the code V\&V plans written to conform to the present quidelines. It is preferable to concentrate on what should be accomplished to achieve success, somewhat independent of anticipated budget. Both ASCI and weapons program oversight will prioritize $\mathrm{V} \& \mathrm{~V}$ requirements across the ASCI code projects at Sandia and fund accordingly.

6. Prime responsibility for the development and implementation of the current plan will reside with one identified member of the code team. This person serves the role of Principal Investigator for the specific code V\&V project.

The V\&V plans will also be used for Sandia V\&V program management purposes, such as tracking the tasks and milestones associated with the annual V\&V ASCI Implementation Plan, costs, and integration with other ASCI program elements. The $\mathrm{V} \& \mathrm{~V}$ plans address these management issues in a variety of ways:

- Identifying one member of the code team responsible for the code's V\&V activity enhances accountability for $\mathrm{V} \& \mathrm{~V}$ within each individual code project to the larger Sandia V\&V program.

- Integral V\&V challenges within Sandia and across the Tri-Lab ASCI V\&V Program are better defined.

- The execution of periodic internal and external peer reviews of the individual code V\&V plans improves the overall quality of the Sandia V\&V program. V\&V plans consequently adapt and improve to the dynamic ASCI and DP environment at Sandia. 
- The ASCI V\&V program at Sandia achieves maximal effectiveness of the required experimental validation and research components of the $V \& V$ plans for specific codes. Once the V\&V plan content is generated based on the following sections of this document, the $V \& V$ program will have more detailed understanding of the experimental requirements needed for success of code $\mathrm{V} \& \mathrm{~V}$ plans. 


\section{Stockpile Drivers, Needs, and Requirements}

The DOE/DP's Strategic Computing and Simulation Validation and Verification Program Plan [1] describes the vision for verification and validation as establishing "confidence in the simulations supporting the stockpile Stewardship Program through systematic demonstration and documentation of the predictive capability of the codes and their underlying models." To achieve this vision, each Sandia ASCI code's V\&V activities should be driven by stockpile requirements: Therefore, precisely defining the stockpile requirements as they relate to each code project is paramount. This section describes the process guidelines for developing $\mathrm{V} \& \mathrm{~V}$ requirements in a form useful for formal code V\&V plans.

The stockpile requirements that govern the Sandia ASCI applications codes are found in the Stockpile Life Extension Plan (SLEP), Albuquerque Work Load Planning Guidance (AWLPG 99-0), the P\&PD, and the detailed needs of each weapon system design group. These requirements determine the needs which, in turn, influence the development of model and software requirements and ultimately the $V \& V$ requirements. In the following, we refer to the highest-level stockpile requirements that directly influence the model and software requirements of a Sandia ASCI code project as stockpile drivers.

We have illustrated the flow of information that begins with the specification of stockpile drivers and ends with V\&V requirements for a code project in Figure 1. The important thing to emphasize about this view is that essentially all of the $V \& V$ process starts from the stockpile drivers for the code project. An accurate understanding of stockpile drivers and the translation of this understanding into code requirements is of critical importance for the definition and success of the V\&V plan for a code.

Understanding the stockpile drivers and determining and developing detailed stockpile needs should be done in coordination with key Sandia DP personnel (e.g. nuclear weapons design community, weapon systems groups, and NWSBU personnel) who are stakeholders in the specific code development project. A key strategy is to identify the right stakeholders, although the correct approach for doing this will vary with the code project. Detailed requirements must then be developed for both code models and code software. The code's V\&V plans are to be written for each stockpile driver of that code. Thus, we actually seek to cast these DP stakeholder requirements as "certification" or "accreditation" requirements, if at all possible. If this classification of the stakeholder requirements is successful, then satisfying these requirements at some point will insure the future acceptance of a code's modeling capability within the DP community at Sandia, a most important goal.

The development of stockpile, model, and V\&V requirements is partially dependent upon the specific code project. For example, individual codes will vary in terms of the effort expended in developing requirements, the amount of detail available at the start of the 
planning process, or how sensitive the V\&V plan will be to variability in the DP program at Sandia. However, each written plan should clearly demonstrate the level of effort expended to understand and document the customers' requirements at the time of writing.

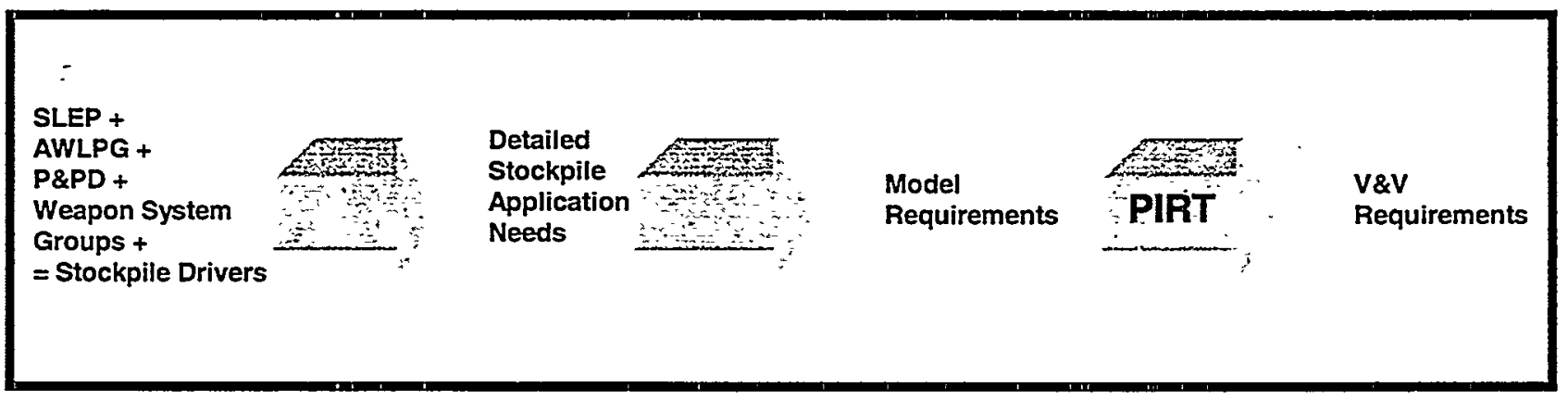

Figure 1. Logic flow of requirements in the Sandia $V \& V$ plans.

When developing the third section of the V\&V plan, the "Phenomena Identification and Ranking Table," (see the Appendix for the recommended Table of Contents for Sandia $\mathrm{V} \& \mathrm{~V}$ plans) the following questions are of concern:

- What stockpile driver and associated DP applications does the code V\&V plan target?

- Who are the DP customers for the stated application?

- When must the code be capable of supporting important milestones in the weapons program directed at the stated application?

- What is the intended impact of the code impact on DP in reference to the stated application?

- What previous DP development or testing activities will be supplemented or replaced by the code if the code is accredited (or certified) for the intended application?

These questions, if not directly answered in the discussion of stockpile drivers, provide underpinning to that discussion. Once determined, for each code's selected stockpile driver the detailed stockpile requirements and their impact on code application requirements must be prioritized. This information will appear in a "Phenomena Identification and Ranking Table" which will describe the required physical phenomena and their associated models needed in the code. We will discuss this next. 


\section{Phenomena Identification and Ranking Table}

Stockpile requirements ultimately govern the fidelity requirements of the code. The fidelity requirements must be defined and assessed in terms of the identification, mathematical formulation, and software implementation of the key physical phenomena modeled by the code. While stockpile drivers originating in the SLEP, AWLPG 99-0, the $\mathrm{P} \& \mathrm{PD}$, and the detailed needs of each weapon system design group are necessary for this task they are not sufficient. A tool is needed to refine stockpile drivers into a more sufficient set of requirements that can serve as the basis for requirements-based code V\&V. The "Phenomena Identification and Ranking Table" (PIRT) is the tool that we have selected to help define the key physical phenomena. The PIRT also ranks the importance of each code model activity associated with the phenomena. A PIRT is an intermediate and necessary step for developing code V\&V plans. The PIRT is a logical connection between stockpile requirements and the modeling priorities that drive code $\mathrm{V} \& \mathrm{~V}$ activities.

The PIRT represents three dimensionally the refined model requirements that result from stockpile applications. First, the PIRT identifies a set of needed physical phenomena to which code V\&V requirements directly map. Second, the PIRT prioritizes the relative importance of the needed physical phenomena to the DP modeling and simulation objectives of the code. Third, the PIRT prioritizes the presumed ability of the code to accurately represent and implement the needed physical phenomena.

The PIRT systematically identifies physical phenomena required for the modeling and simulation needed by the chosen stockpile. These are the phenomena the code must ultimately address, formulate, and implement to succeed in its stockpile mission. The phenomena must be prioritized and the criteria applied to accomplish this must be described. Finally, the adequacy or inadequacy of current models of the phenomena and their implementation must be discussed.

To develop a PIRT appropriate for use in a code V\&V plan, the following basic questions must be answered:

- What is the overarching stockpile driver for which the PIRT is developed?

- What physical phenomena, ranked by importance for the stockpile applications targeted by the code, must be implemented (first in mathematics, then in software) to allow these code applications? How was the importance established? 
- How are these phenomena assessed in terms of the accuracy of their current software implementation? Can a similar assessment be performed aiming at a potential future implementation if some phenomena are not currently implemented in software?

- What major technical risks is Sandia assuming by developing software that implements these phenomena and supports their stockpile applications?

- How accurate must the software be to support the required stockpile applications? How is this decision made?

- What are the consequences of erroneous, or inaccurate, calculations for the contributing applications?

Let us now consider several examples of a PIRT. The important fact to emphasize is that there are many possible forms of a PIRT. It is important that specific code projects use a form that is compatible with their stockpile requirements as well as their codes.

The first example is given in Figure 2. There, a generic form of PIRT has been presented. The underlying assumption is that there is one stockpile driver (not stated in the table), and that two phenomena must be modeled to successfully apply the code to the driver. Two columns give hypothetical answers to questions of (1) how important the specific phenomenon is to the modeling goals and (2) an assessment of adequate the current status of this phenomenon is. For example, phenomenon \#2 could be in a research status, hence unsatisfactory for stockpile applications, while phenomenon \#1 could be modeled by a piece of software that can be purchased. We have also suggested one approach for performing the ranking and prioritization - via purely qualitative measures. How appropriate this is must be a decision a particular code project makes.

\begin{tabular}{|c|c|c|}
\hline Phenomenon & Importance & Current Adequacy \\
\hline$\# 1$ & Less & Adequate \\
\hline$\# 2$ & More & Inadequate \\
\hline
\end{tabular}

Figure 2. A Phenomena Identification and Ranking Table (PIRT) - the simplest case.

Another, incrementally complex example, is given in Figure 3 . The general features of this PIRT are similar to Figure 1. We have simply demonstrated that we expect that for ASCI codes, the summary of phenomena will be more complex than suggested by the 
PIRT in Figure 1. We have continued to use qualitative ranking and prioritization in columns two and three of the PIRT in Figure 3.

\begin{tabular}{|c|c|c|}
\hline Phenomenon & Importance & Current Adequacy \\
\hline$\# 1$ & Less & Adequate \\
\hline$\# 1-\mathrm{A}$ & Less & Adequate \\
\hline$\# 1-\mathrm{B}$ & More & Inadequate \\
\hline$\# 2$ & More & Inadequate \\
\hline$\# 2-\mathrm{A}$ & More & Adequate \\
\hline$\# 2-\mathrm{B}$ & More & Inadequate \\
\hline
\end{tabular}

Figure 3. A Phenomena Identification and Ranking Table (PIRT) - a slightly more complex case.

Figure 4 shows an example of a PIRT that is the same as that in Figure 3, except that the rankings are now quantitative. Both importance and current adequacy are ranked on a hypothetical quantitative scale from 1 to 4, with 4 "highest" for column two, "Excellent" for column three, and 1 "lowest" for column two, "unusable" for column three. The ability to generate a meaningful numerical ranking of this type is obviously highly dependent upon the stockpile driver, the nature of the code project, and the intended evolution of that project.

\begin{tabular}{|c|c|c|}
\hline Phenomenon & Importance & Current Adequacy \\
\hline$\# 1$ & 2 & 3 \\
\hline$\# 1-A$ & 1 & 4 \\
\hline$\# 1-B$ & 2 & 3 \\
\hline$\# 2$ & 3 & 4 \\
\hline$\# 2-A$ & 3 & 3 \\
\hline$\# 2-B$ & 4 & 2 \\
\hline
\end{tabular}

Figure 4. A Phenomena Identification and Ranking Table (PIRT) - a slightly more complex case with quantitative rankings.

Figure 5 extends the PIRT example in Figure 4 to a case where multiple detailed applications of the code are represented in the PIRT. How can this happen in reality? To 
illustrate, in the case of ALEGRA-EMMA, there are two major applications of the code intended for studying NG power supplies. One (say "Use A") is to apply the code to power supply design studies. The other (say "Use C") is to apply the code in certification activities for future power supply designs. Each application or use of ALEGRA-EMMA relies on the same phenomena for the modeling and simulation. Why do we prioritize each independently in a PIRT like Figure 5? Because the stockpile stakeholder(s) in that case have told that code that the accuracy requirements are significantly different between the two uses. In such a case, we easily see that each use might rank phenomena both by importance and current implementation capability differently. For one thing, a phenomenon, which might be suitably currently implemented for design, might be inadequately implemented for a certification study. On the other hand, a phenomenon might not be important to achieve the accuracy required for design, but could be a very important for certification. In fact, a PIRT similar to that in Figure 5 has been developed for the ALEGRA-EMMA V\&V plan.

\begin{tabular}{|c|c|c|c|c|c|c|}
\hline \multirow{2}{*}{ Phenomenon } & \multicolumn{3}{|c|}{ Importance } & \multicolumn{3}{c|}{ Current Adequacy } \\
\cline { 2 - 8 } & Use A & Use B & Use C & Use A & Use B & Use C \\
\hline$\# 1$ & 2 & 3 & 4 & 3 & 3 & 2 \\
\hline$\# 1-A$ & 1 & 3 & 3 & 4 & 3 & 2 \\
\hline$\# 1-B$ & 2 & 4 & 4 & 3 & 2 & 1 \\
\hline$\# 2$ & 3 & 3 & 4 & 4 & 3 & 1 \\
\hline$\# 2-A$ & 3 & 3 & 4 & 3 & 2 & 1 \\
\hline$\# 2-B$ & 4 & 3 & 4 & 2 & 3 & 2 \\
\hline
\end{tabular}

Figure 5. A Phenomena Identification and Ranking Table (PIRT) - a slightly more complex case with more quantitative ranking approach and more than one way of using the code for the stockpile requirements.

Figure 6 is an illustration of a subset of a PIRT under development for the PEGASUS NG neutron tube modeling code. In this example, the stockpile driver is to predict the performance of NG neutron tubes. This phrase presents an example of a main stockpile driver. We observe that this stockpile driver also includes more than the specific application for which PEGASUS is being developed. For example, included under this stockpile driver is the need to model the NG power supply, a stockpile driver for the ALEGRA-EMMA code.

In Figure 6, the stockpile driver has been refined into two broad requirements on the code, similar to our discussion of Figure 5: (1) to quantitatively predict neutron production and (2) to qualitatively predict trends resulting from design changes. These more specific stockpile requirements then determine the phenomena which are required in 
the PEGASUS modeling. In the case of Figure 6, these phenomena are identified in column one. We discern from study of Figure 6 that the phenomena have been refined to have three major categories (similar to the very crude example in Figure 3). The highest level is illustrated by only one line in this subset of the original PIRT - "PLASMA CUP". The identifiers C-1 ("Inflow Description"), C-2, and so on designate an intermediate level. The lowest level is designated by C-2-a) "Secondary Electron Emission", for example.

The three dimensions we seek in a PIRT are clearly identified in the example in Figure 6. The associated physical phenomena are identified, their importance to the two major code requirements is ranked in the middle two columns, and an assessment of the current status for the phenomena model formulation and implementation is given in the right column.

Our V\&V plans must contain a PIRT for the targeted stockpile driver. The PIRT is an essential bridge between the stockpile driver and the detailed code-centered requirements that drive validation, as suggested in our logic flow diagram in Figure 2, which is a more detailed extension of the simple diagram in Figure 1. It is essential that the PIRT also be consistent with the five-year planning milestones developed for the code in the Sandia ASCI Five Year Plan [4].

We can not provide rigid guidance on the presentation of a PIRT. The development of the PIRT depends on how elaborate the application of the code is vis a vis the stockpile requirements. Whether a quantitative ranking or only a qualitative ranking should be attempted depends greatly on what the stockpile stakeholders are telling the code project about how the code should be used. We have not even illustrated all of the potential content of a PIRT. For example, it might be useful to indicate in the PIRT whether, when a phenomenon is suggested as having inadequate current modeling, the weight of the work of improvement is believed to be in verification or validation. Not all model improvements are solely validation problems.

The PIRT is obviously critical for validation activities, because the modeling status, importance and completeness of the phenomena identified in the PIRT are fundamental information needed to focus the code's validation effort. Yet, the PIRT is also an important guiding principle for code verification. As one illustration of why this is the case, note that concern about mathematical formulation and implementation accuracy is one focus of the PIRT, where we attempt to assess the current status of a model. The priorities of the PIRT clearly serve to focus verification activities, particularly the verification testing activities discussed below. A verification test plan should mirror the priorities given in the PIRT. Thus, discussion of the logic behind verification test plans for the code (requested below) should have some connection to the priorities established by the PIRT.

We will end this section by briefly appraising where we are in the V\&V guideline definition process. Consider Figure 7. This flowchart suggests what the remainder of this 
document discusses. Figure 7 should be contrasted with Figure 1, which was a description of one part of the overall logic flow. That part is replicated in Figure 7, with the boxes labeled 1 through 4 . Our remaining effort in this document is to discuss the issues involved in tracking this flow chart into both the verification and the validation activities.

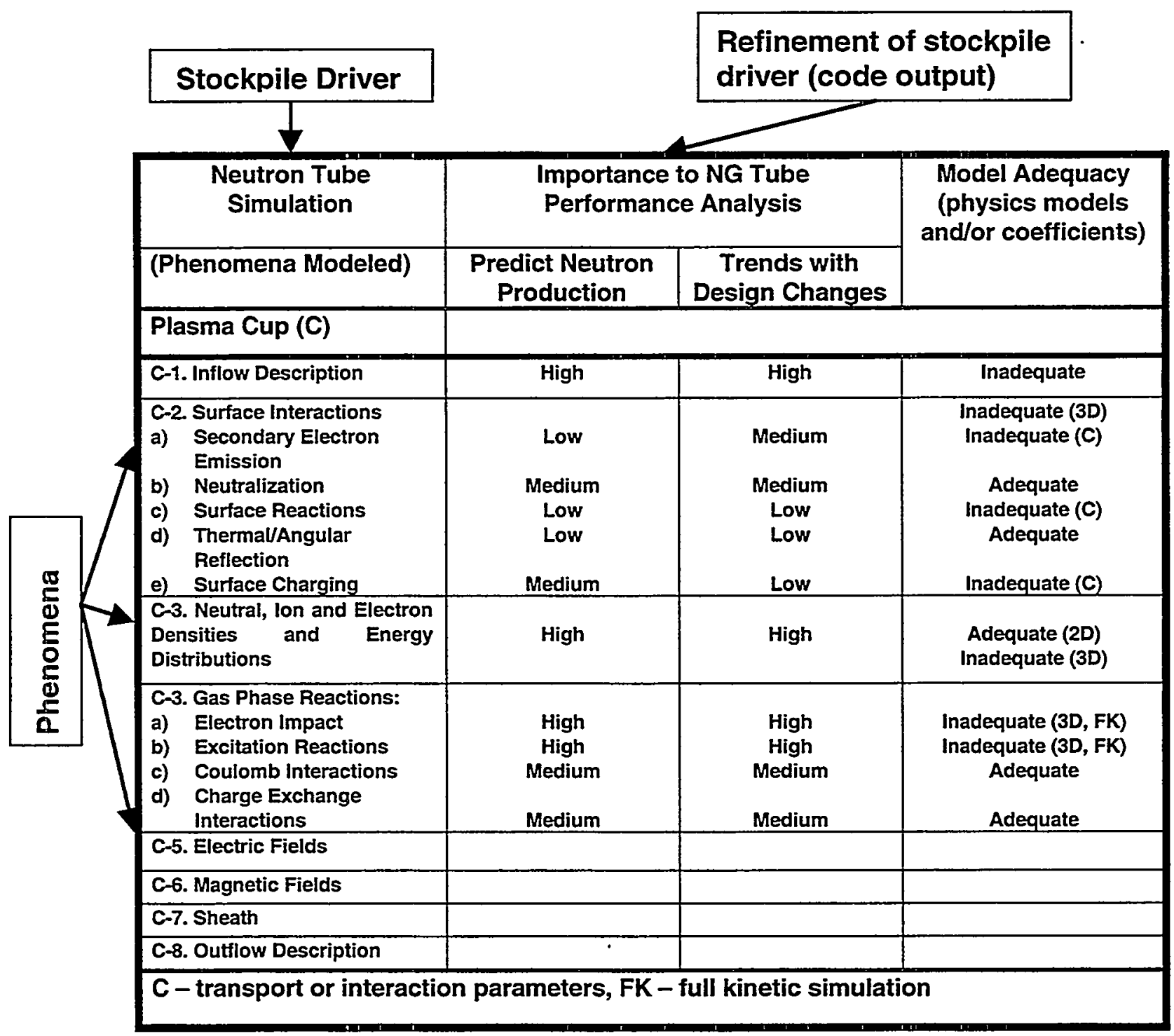

Figure 6. A partial Phenomena Identification and Ranking Table (PIRT) for a complex stockpile application involving a NG neutron tube (Johannes, Private Communication). 
From a programmatic view the most important part of our guidelines has been defined. That is, we have emphasized the need for an accurate presentation of requirements and, with its culmination in the development of a PIRT. We reiterate that there are two main reasons for attaching so much importance to the exposition of requirements. First, they insure contact of our V\&V efforts with DP at Sandia. Second, our chosen model for the actual practice of verification and validation is "requirements based V\&V." This model emphasizes that code V\&V follows logically from code requirements. We now turn our attention to guidelines for both verification and validation test plans. 


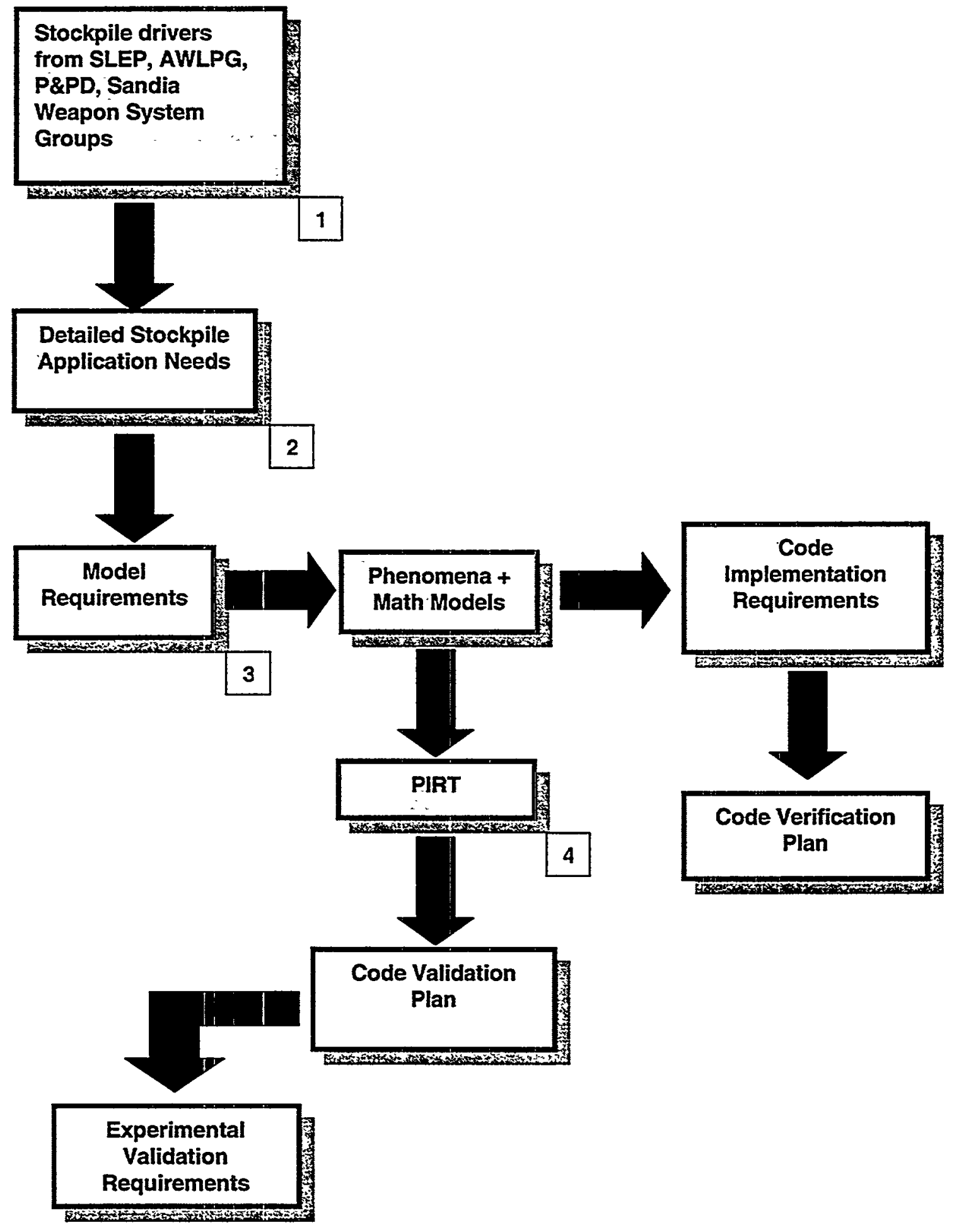

Figure 7. The logic flow revisited: Flowchart of the needed content for Sandia ASCI Code V\&V plans. 


\section{Software Verification Requirements and Verification Plan}

\section{A. Defining Software Verification Requirements}

In addition to the validation requirements code verification requirements also emerge from the PIRT. The PIRT emphasizes the implementation needs for the code, along with priorities. Therefore, the PIRT connects the software implementation priorities to the stockpile driver. Focus on mathematical models is required in developing the PIRT and this was one of the boxes that we used in the flowchart in Figure 7. We presume that some kind of assessment of the math models underlying the software implementation of the phenomena listed in the PIRT has also been performed to develop priorities. This assessment also provides natural focus opportunities for the software verification process. For the purposes of this document we regard such an assessment as primarily a code development activity.

The ultimate goal of the software verification process is to increase our confidence in the implementations of the required phenomena and their numerical characterization. The V\&V plans should address three content areas for the verification plan - software quality assurance (SQA), software engineering methodologies (SE), and the verification testing process. Information and priority guidance from the PIRT tends to intersect all of these areas. However, the PIRT can also aid in designing and applying the verification test plan. This test plan must clearly address verification requirements that are emphasized in the PIRT. For example, we expect that the intensity and degree of effort to be applied in verification testing will correspond to the priorities established in the PIRT. The complexity of verification testing also reflects the complexity of the phenomena detailing in the PIRT. Similarly, the priorities of the PIRT, and synergism of the phenomena listed there, may also provide guidance for where to implement and formalize SE or SQA activities for the code.

The level of detail and the relevance of the software verification requirements will depend on the specific code project and its PIRT, as well as on the anticipated complexity of the verification test process. For purposes of the peer review that the V\&V program will initiate enough detail is required to understand the definition of the verification requirements and their impact on the verification test process.

Two questions need to be posed in order to determine if the software verification requirements were fulfilled. Why was the verification test suite chosen? How was the verification test suite chosen? A clearly defined requirement should lead to a need for testing, for some specific SE methodology, or for some reliance upon a particular 
paradigm in SQA. On the other hand, a test problem taken in isolation should also have an implied software verification requirement associated with it. It may be true in this latter case that this requirement will have to be "reverse engineered."

The code V\&V plans should include:

- Detailed descriptions of software verification requirements, accompanied by metrics for tracking and measuring success.

- Linkage of the verification requirements to (1) the specific verification test plan of the code and (2) the lesser or greater need of the code project for formal SQE.

The verification requirements and their metrics serve as the most basic instrument that we can apply to assess the progress of the verification process for the code. We also emphasize once again that it is implicit that all V\&V plans will be subject to periodic revisions, reflecting inexorable changes in development priorities. The plan should simply attempt to develop the best coherent picture of the requirements that are driving code development available at the time of writing and at those times of periodic revision. It is also appropriate to give some definition to the expected revision process. This could be done, for example, under a formal requirement management framework specified in the V\&V plan.

\section{B. Software Verification Plan}

Once the software requirements have been identified and defined, the verification section is ready to be written. This section should focus on software implementation, its correctness and its effectiveness. As discussed previously, the level of detail will depend on a specific code; however, sufficient information is necessary to allow management and peer reviewers to assess the success of the verification effort.

The verification section should include:

- An overview of the process used to develop the software and the software quality principles applied.

- A description of software engineering techniques used by the project to produce the software.

- The testing methods applied to the code. 


\section{Software Development Process}

We choose to base the description of the software development process for the Sandia ASCI codes on the principles of the Software Engineering Institute's Capability Maturity Model (CMM), specifically Level II [5]. There are several key processes defined and documented within CMM Level II which all Sandia ASCI code projects should discuss in the V\&V plans:

\section{Requirements management;}

2. Project planning;

3. Project tracking and oversight;

4. Sub-contract management;

5. Software Quality Assurance (SQA);

\section{Configuration management.}

Although all of these processes are already being used on Sandia ASCI code projects, the levels of rigor vary. Requirements management is implicit in the formation of the projects, and will be formalized through direct implementation as part of the code's associated $V \& V$ program. We have explained above our rationale for requesting requirements information in the V\&V plans. Project planning is currently exemplified by the evolving ASCI five-year planning effort. The necessity of linking that project plan's milestones to our $V \& V$ requirements was stressed previously in this document.

Project tracking and oversight vary in intensity from project to project. But, the fact that the individual code five-year plans are.living documents is evidence for the need to perform project tracking. The stated purpose of project tracking in reference 5 is to "provide adequate visibility into actual progress so that management can take effective actions when the software project's performance deviates significantly from the software plans." Thus, this component is important for managing the V\&V program. Because the $\mathrm{V} \& \mathrm{~V}$ program needs to be flexible to changing project milestones, it must also track them.

We interpret sub-contract management to mean effectively dealing with requirements such as the experimental requirements suggested in the last bullet on page 5 , as well as managing the interface between the software project and its targeted hardware platforms. 
It simply means effectively working with key external suppliers for the code project. An SQA process provides management with "appropriate visibility into the process being used by the software project and of the products being built [5]." We place this within the overall context of code verification because it is relevant to assessing the "correctness" of the software implementation, the ultimate goal of verification.

All ASCI code projects at Sandia are applying configuration management principles at this time. CMM considers this software engineering technique a Level II process because of its perceived importance as a device for controlling the accuracy of the software implementation. It is the most fundamental of such control devices. Because it deals with implementation accuracy, its description is properly part of the verification component for the code $V \& V$ project.

A decision has not yet been made as to what level of rigor to pursue CMM Level II within the ASCI code development community. This is essentially a cost versus benefit issue that does not have adequate metrics associated with it at this time. However, by providing information needed to assess to Level II in our V\&V plans, we will also provide data that may allow a cost-benefit analysis to be performed in the future.

\section{Software Engineering Techniques Applied in the Code Development}

A variety of information is needed to fully define the general verification tasks listed above. For example, some of the information below is properly part of a description of the CMM Level II processes, while some is in addition to a discussion of CMM. Whether given in the SQA discussion or in the current SE discussion, the following information should be provided as part of the $\mathrm{V} \& \mathrm{~V}$ plan, if relevant to the particular code:

- Use of programming standards and style guide (if used);

- Use of software inspections (if used);

- Use of regression testing (if used); .

- Application of coverage tools (if applied);

- Definition and use of configuration management systems (if used);

- Definitions of bug tracking systems and bug resolution techniques (if applied);

- Description of the overall code development environment, including the terascale implementation constraints as well as other targeted hardware information;

- Description of the metrics for gauging the effectiveness of the software development process; 
- Description of the software development process modification strategies;

It is important to accurately convey the logic of the software development process. This information needs to be provided in sufficient detail to expedite internal, as well as external, peer review.

\section{Issues and Challenges}

It is also critical to devote attention in the verification plan to discussing challenges in the software development process, and its supporting software engineering and quality environments. What should be done but isn't? What are desirable targets for improvement? How would additional expertise in either software quality assurance or software engineering or both improve the software implementation process? What is unique or valuable about the software development approach? How is the information measured? This information transcends what we are asking for the CMM Level $\Pi$ process data.

\section{Software Testing Process}

The description of the software testing process should include the following information:

- Numerical Methods. A discussion of the numerical methods and the process for improving numerical quality of the software is needed, or needs to be referenced. In particular, an important issue is the linkage of the verification test suite to this discussion. Such a discussion should include documentation, or reference to such documentation, of the basic equations to be solved by the software and the numerical methods used to achieve this solution, and how the verification test suite is designed to test these methods. In the absence of such documentation, a process with a timeline for developing this documentation should be presented.

- Additional software. Reliance upon auxiliary software should be discussed. Algorithmic performance metrics should be described. Consistency and quality metrics for evaluating the algorithmic quality of the software should be described.

- Other Technologies. What supplementary technologies are used or would be useful? For example, if sensitivity analysis is used, describe the technology and its intended application in the verification activities.

- Test Suite. Description of the verification test suite (compatible with the ASCI V\&V Program Implementation Plan) and its use.

The verification test suite applied to the code should be further refined in a three tier taxonomy. The three tiers are defined as follows: 
1. Tier I - tests with exact analytical solutions;

2. Tier II - tests with semi-analytic (reduction to quadrature, to simple ordinary differential equations, etc) solutions;

3. Tier III -idealized problems suitable for code comparison exercises.

There will always be some classes of problems that do not fall strictly into these categories. For example, sanity checks, such as tests of conservation of energy or preservation of symmetry, may be used for problems that do not have either analytical or semi-analytical solutions. Common sense should govern how to categorize such problems, depending on the particular needs of a specific code project. The above three categories of problems are of clear relevance to most scientific code development and provide a core description for most verification test suites.

It is important to convey the logic of the test suite. A simple question the author(s) of the $\mathrm{V} \& \mathrm{~V}$ plan for a specific code should ask themselves when discussing the verification suite is: "Will someone new to the code development project be able to decipher the goals and constraints of the test suite from the evolving V\&V plan?" The definition of the test suite should also include discussion of accuracy assessments or metrics associated with each tier. In particular, there should be some definition of acceptance testing levels when is the accuracy of the code performance on specific elements of the test suite good enough? 


\section{Software Validation Requirements and Validation Plan}

\section{A. Defining Validation Requirements}

As discussed in Section III, a PIRT connects key stockpile requirements to key physical phenomena implemented in the software. The most important component of the validation requirements is establishing logical linkage of the PIRT to key code validation milestones. The V\&V plan should also document the strategy to be applied for assessing the physical basis and degree of accuracy of the mathematics implemented in the evolving software product.

The following information is required for suitably documenting the validation requirements:

- Establish connections between the validation test plan and the PIRT information discussed in section II.

- Describe the origin of the physical models in the stockpile requirements.

- Discuss the data requirements associated with this validation activity.

- Describe the known dependence of assessment of the quality of the physical content of the software upon experimental data.

- State the critical assumptions underlying the implemented physical models.

- Describe how these assumptions may or may not be subject to experimental investigation.

- State the dependence of the software upon experimentally measured quantities; describe critical experimental facilities or capabilities that must be applied to generate these quantities; state the role of calibration for using these data in the ultimate accuracy of the software.

\section{B. Software Validation Plan}

The validation plan for the code, focused on the stockpile application presented in the first section, must have three main components. First, we require the description of a 
four-tiered validation test suite (described below) designed to test the validity of the code upon the stated application. Second, an associated experimental program description is required, mainly aimed at addressing the highest priority data needs that emerge in the requirements discussion. Third, supplementary "technologies" that are perceived to be needed to support the code validation effort should be described.

The validation plan should contain the following information:

- A four-tiered validation suite to be applied to the code (mainly compatible with the ASCI V\&V Program Implementation Plan). Describe the tests. Describe the logic for selecting the tests and for assessing their expected impact on the validation objectives. Describe the expected impact on customer requirements of using the test plan. Describe the metrics used to assess data quality for use in the various tiers of the validation test suite.

- Define the experimental validation component intended to provide new data, experimental facilities, specialized diagnostics and test equipment, and experienced personnel. What are the constraints on the quality of the data for it to be applicable to the code $V \& V$ program?

- What supplementary technologies are used or would be useful for validation? For example, if uncertainty quantification is to be applied as part of your validation strategy, describe the technology and its use. How are these technologies implemented?

Similar to the verification component, we are interested in a tiered approach to the validation testing plan. A loose structuring of the tiers is as follows:

Tier I - Designed to measure the degree of accuracy to which separable effects (or single phenomena) in the code correctly represent the real world.

Tier II - Designed to measure the degree of accuracy to which coupled effects between distinctly identified phenomena in the code correctly represent the real world.

Tier III - Designed to to measure the degree of accuracy to which integral phenomena in the code, in which many coupled effects may be present, correctly represent the real world.

Tier IV - Designed to be a "Certification Experimental Campaign" or confirmatory experimental activity designed to measure the readiness of the code for stockpile computing and application to stockpile problems. It is essential that this be 
performed in conjunction with the weapon design community and in coordination with additional experimental opportunities that may arise in the normal course of nuclear weapon program work at Sandia.

Ascending this set of validation problem tiers increases the complexity of the associated validation activity, as well as the experiments required to support that validation. As confidence is gained at lower complexity, the complexity of the validation activity should increase. This continual process should aim to establish ultimate confidence in the physical accuracy of the software to represent the geometric complexity and the breadth of the physical phenomena needed by the ultimate stockpile drivers. At this point, one would expect carefully instrumented full-system hardware/model confirmatory experiments to be conducted synergistically with the code project (Tier IV). Movement through the tiers also intrinsically focuses experimental components of validation testing.

The logic by which the code project expects to ascend this set of tiers should be presented in detail in V\&V plans. Here, for example, is one important application of the PIRT analysis. PIRTs can be used to order the effort expended on first separable, then coupled phenomena, to best achieve the final integral capability. A defined certification activity can also be used to organize a validation effort aimed at ascending these tiers. Code projects should be able to develop evidence of their ability to ascend the tiers, or to identify roadblocks that prevent them from doing this, such as missing experiments.

\section{Protocols for Stockpile Computing}

Our code V\&V plans should describe and justify the protocols for doing stockpile calculations aimed at the defined stockpile driver. For instance, V\&V plans should document how the code project expects its product to be used for high consequence stockpile calculations. The scope and formality of the protocols must be consistent with the documented requirements. The purpose of defining protocols for stockpile calculations is to ensure that software is used properly in making decisions about nuclear weapons. All simulations have anticipated limitations on their use, and these must be understood and described in the V\&V plans.

Appropriate circumstances for doing stockpile calculations should be designated. Required user expertise for performing such calculations should be described. For example, should a user for a stockpile calculation have participated in the confirmatory (Tier IV) validation activity associated with the code? Should users be formally trained in the use of the code? 
The entire expected simulation process for potential stockpile applications should be documented in reproducible detail.

Extreme care is warranted for the most critical applications. Various measures should be documented in the plan if selected. These should include:

1. Description of the accredited use of the code. This may include, but is not restricted to, discussion of construction and archiving of code inputs, guidance for mesh convergence studies, and material property requirements for stockpile computing.

2. Description of how analysts will be accredited to ensure that they have the necessary expertise to use these tools for particular applications.

3. Description of methods used for scrutinizing stockpile simulations with peer review.

4. Description of methods used for auditing the simulation process to guarantee that test problems are successfully completed, configuration control is maintained, necessary information is archived, and documentation is completed.

The intent of these requirements is to establish a baseline for application of the software to high consequence stockpile applications. 


\section{Conclusions}

The purpose of this report is to state guidelines for content appropriate for the development and documentation of Verification and Validation plans for ASCI code development projects at Sandia. We have chosen to emphasize requirements driven $\mathrm{V} \& \mathrm{~V}$. This conscious choice has given the stockpile requirements which lie at the heart of the intended applications of the Sandia ASCI codes for Science Based Stockpile Stewardship the most important role in the entire planning process. Our view is most succinctly expressed in Figure 1, which shows all anticipated logic in the V\&V plans flowing from the underlying stockpile drivers for the code development activity.

With this choice of approach, the content we recommend for Sandia V\&V plans consists of four major items:

- The stockpile drivers supported by particular modeling applications of the code.

- Phenomena required for modeling to be successful to support the required stockpile drivers and their relative importance to the modeling. A Phenomena Identification and Ranking Table (PIRT) is the device we recommend for expressing this information.

- Verification activities designed to assess and improve correctness of the software implementation of these phenomena.

- Validation activities designed to assess and improve correctness of the models that are implemented in the code as guided by the PIRT.

There are other strategies for developing V\&V plans, such as specification-based V\&V, which would give other elements in a code development project higher priorities. We believe that our view, which stresses the ultimate importance of the stockpile applications for the code, is certainly more practical for ASCI code development projects. We also believe that our suggested approach is compatible with our view that we are narrowly validating codes for specific applications, rather than attempting to validate codes in some entirety. We actually believe that the latter goal is impossible. On the other hand, focusing $\mathrm{V} \& \mathrm{~V}$ plans and activities at assessing the competence of a code for performing a specific set of modeling activities seems to us to be fully possible. Our recommended guidelines in this report provide a basis for making such assessments. 
(Page left blank.) 


\section{References}

1. U.S. Department of Energy Defense Programs, "Strategic Computing \& Simulation Validation \& Verification Program," April 20, 1998 (Draft).

2. Sandia National Laboratories, ASCI V\&V Program Office, "Strategic Computing \& Simulation Validation \& Verification Program Implementation Plan," May 1998 (Draft).

3. J. R. Lee (1998), "Certainty in Stockpile Computing: Recommending a Verification and Validation Program for Scientific Software", Sandia National Laboratories Report SAND98-2420.

4. Sandia ASCI Five-Year Plan. See, for example, "ASCI Applications FY99 Implementation Plan for Nuclear Weapons System Engineering and Components," R. K. Thomas, Sandia ASCI Applications Program Office Document.

5. Carnegie Mellon University Software Engineering Institute (1994), The Capability Maturity Model: Guidelines for Improving the Software Process, Addison-Wesley, Reading, MA. 
(Page left blank.) 


\section{Appendix: Sandia ASCI V\&V Plan Table of Contents}

The recommended form of V\&V plans for ASCI codes at Sandia should have a Table of Contents given as follows:

Executive Summary

Section 1: Stockpile Drivers and DP Customer Requirements

Section 2: PIRT

Section 3: Verification Plan

3.1 Verification Requirements

3.2 Software Development Process Description - SQA and SE

3.3 Software Verification Testing Plan

Section 4: Validation Plan

4.1 Validation Requirements

4.2 Validation Experimental Requirements

4.3 Validation Testing Plan

References 
(Page left blank.) 


\section{Acknowledgements}

The guidelines we publish in this document have been heavily influenced by the 1998 ASCI V\&V Draft Program Plan, the Sandia 1999 ASCI V\&V Implementation Plan, and the people who developed those plans. We also greatly benefited from the Sandia report authored by James R. Lee in 1998, which recommended the development of ASCI V\&V plans having specific forms at Sandia. We would like to thank Randy Summers and Gene Hertel for critically reviewing this document prior to publication. Many other people commented on earlier drafts of the present report, including Reeta Garber, Bill Tedeschi, David Peercy, Ann Hodges, and Bill Moffat. We would like to thank them at this time for their comments.

This work was supported by the United States Department of Energy under Contract DEAC04-94AL85000. Sandia is a multiprogram laboratory operated by Sandia Corporation, a Lockheed Martin Company, for the United States Department of Energy. 
(Page left blank.) 
Distribution

EXTERNAL DISTRIBUTION

Adams, M. A.

Jet Propulsion Laboratory

4800 Oak Grove Drive, MS 97

Pasadena, CA 91109

Anderson, Charles E.

Southwest Research Institute

P.O. Drawer 28510

San Antonio, TX 78284

Anderson, D.

Graduate Aernonautical Laboratories

California Institute of Technology

1200 E. California Blvd./MS 205-45

Pasadena, CA 91125

Aivasis, $\mathrm{M}$.

Center for Advanced Computing

Research

California Institute of Technology

1200 E. California Blvd./MS 158-79

Pasadena, CA 91125

Anderson, $\mathrm{M}$.

ACTA

2790 Skypark Dr., Suite 310

Torrance, CA 90505-5345

Ayyub, B. M

University of Maryland

Civil Engineering - Rm. 1155

College Park, MD 20742-3021

Beissel, S.

Alliant Techsystems Inc.

600 Second St. NE

Hopkins, MN 55343
Belytschko, $\mathrm{T}$.

Northwestern University

Dept. of Mechanical Engineering

2145 Sheridan Road

Evanston, IL 60108-3111

Cafeo, John A.

General Motors

Research \& Development Center

Mail Code 480-106-256

30500 Mound Road

Box 9055

Warren, MI 48090-9055

Casteel, $\mathrm{K}$.

University of Texas - El Paso

$600 \mathrm{~W}$. University Ave

El Paso, TX 79968-0521

Cavendish, James C.

General Motors

Research \& Development Center

Mail Code 480-106-359

30500 Mound Road

Box 9055

Warren, MI 48090-9055

Chwastyk,T.

U.S. Naval Research Laboratory

Code 6304

4555 Overlook Avenue SW

Washington DC 20375-5343

Cho, $\mathrm{K}$.

Stanford University

Durand 267

Stanford, CA 94305

Colemans, $\mathrm{H}$. W.

U. Alabama Huntsville

S236 Technology Hall

Huntsville, AL 35899 
Coker, D.

Graduate Aeronautical Laboratories

California Institute of Technology

1200 E. California Blvd./MS 105-50

Pasadena, CA 91125

Cosner, R. R.

Senior Technical Fellow

Boeing - Phantom Work

P. O. Box 516, MS: S106 - 7126

St. Louis, MO 63166

Cuniff, $P$.

U. S. Army Soldier Systems Center

Kansas Street

Natick, MA 01750-5019

Diwekar, U. M.

Center for Energy and Environmental

Studies

Carnegie Mellon University

Pittsburgh, PA 15213-3890

Gabrovsek, R.

National Institute of Chemistry

Hajdrihova 19, POB 3430

SI-1000 Ljubljana

Slovenia

Glimm, J. G.

Dept. of Applied Math and Statistics

Math, P138A

State University of New York at Stony

Brook

Stony Brook, NY 11794-3600

Hasselman, T. K.

ACTA

2790 Skypark Dr., Suite 310

Torrance, CA 90505-5345

Hills, R. G.

Department of Mechanical Engineering

New Mexico State University

Las Cruces, New Mexico 88001
Howes, F. A.

U. S. Dept. of Energy

DOE, MICS, ER-31

19901 Germantown Rd.

Germantown, MD 20874

Ivy, G.

Logicon R\&D Associates

P. O. Box 92500

Los Angeles, CA 90009

Kane, $C$.

California Institute of Technology

1200 E. California Blvd./MS 205-45

Pasadena, CA 91125

Karniadakis, G.

Division of Applied Mathematics

Brown University

192 George St., Box F

Providence, RI 02912

Keremes, J.

The Boeing Company

Rocketdyne Propulsion \& Power

6633 Canoga Avenue

Canoga Park, CA 91309-7922

Kimsey, K. D.

U. S. Army Research Laboratory

Weapons and Materials Research

Directorate

AMSRL-WM-TC 309 120A

Aberdeen Proving Ground, MD 21005-5066

Kovac, B. A.

The Boeing Company

Rocketdyne Propulsion and Power

6633 Canoga Avenue

Canoga Park, CA 91309-7922 
Krysl, P.

Department of Computer Science

California Institute of Technology

1200 E. California Blvd./MS 256-80

Pasadena, CA 91125

Liu, W. K.

Northwestern University

Dept. of Mechanical Engineering

2145 Sheridan Road

Evanston, IL 60108-3111

Mair, H. U.

Institute of Defense Analyses

Operational Evaluation Division

1801 North Beauregard Street

Alexandria, VA 22311-1772

McRae, G.

Department of Chemical Engineering

Massachusetts Institute of Technology

Cambridge, MA 02139

McDonald, W.

Naval Surface Warfare Center

Code 420

101 Strauss Avenue

Indian Head, MD 20640-5035

Mehta, U. B.

NASA Ames Research Center

MS: T27 B-1

Moffett Field, CA 94035-1000

Molinari, J.-F.

Graduate Aernonautical Laboratories

California Institute of Technology

1200 E. California Blvd./MS 105-50

Pasadena, CA 91125

Morris, M. D.

Oak Ridge National Lab

P. O. Box 2008

Building 6012

Oak Ridge, TN 37831-6367
Namburu, R.

Director

U.S. Army Research Laboratory

Attn: AMSRI-CI-H (Dr. Raju

Namburu)

APG, MD 21005-5067

Needham, C.

Applied Research Associates, Inc. 4300 San Mateo Blvd. Ste A-220

Albuquerque, NM 87110

Needleman, A.

Brown University

Division of Engineering, Box D

Providence, RI 02912

Omprakash, S.

Graduate Aeronautical Laboratories

Califormia Institute of Technology

1200 E. California Blvd./MS 105-50

Pasadena, CA 91125

Ortiz, M. (5)

Graduate Aeronautical Laboratories

California Institute of Technology

1200 E. California Blvd./MS 105-50

Pasadena, CA 91125

Pace, D. K.

The John Hopkins University

Applied Physics Laboratory

111000 Johns Hopkins Road

Laurel, MD 20723-6099

Papoulia, K.

Inst. Eng. Seismology \& Earthquake

Engineering

P. O. Box 53, Finikas GR-55105

Thessaloniki, Greece

Radovitzky, P.

Graduate Aeronautical Laboratories

California Institute of Technology

1200 E. California Blvd./MS 105-50

Pasadena, CA 91125 
Rafaniello, W.

DOW Chemical Company

1776 Building

Midland, MI 48674

Ran, $\mathrm{H}$.

Graduate Aeronautical Laboratories

California Institute of Technology

1200 E. California Blvd./MS 105-50

Pasadena, CA 91125

Repetto, E.

Graduate Aeronautical Laboratories

California Institute of Technology

1200 E. California Blvd./MS 105-50

Pasadena, CA 91125

Rosakis, A. J.

Graduate Aeronautical Laboratories

California Institute of Technology

1200 E. California Blvd./MS 105-50

Pasadena, CA 91125

Sevin, E.

Logicon RDA, Inc.

1782 Kenton Circle

Lyndhurst, $\mathrm{OH} 44124$

Shu, Y.-C.

Graduate Aeronautical Laboratories

California Institute of Technology

1200 E. California Blvd./MS 105-50

Pasadena, CA 91125

Singleton, $\mathrm{R}$.

Director, Engineering Sciences

Directorate

U. S. Army Research Office

4300 S. Miami Blvd.

P. O. Box 1221

Research Triangle Park, NC 27709-2211
Snowden, W. E.

DARPA

7120 Laketree Drive

Fairfax Station, VA 22039

Stevenson, D. E. (Steve)

Clemson University

Computer Science Department

442 Edwards Hall - Box 341906

Clemson, SC 29631-1906

Sundaram, S.

Graduate Aeronautical Laboratories

California Institute of Technology

1200 E. California Blvd./MS 105-50

Pasadena, CA 91125

Thoutireddy, P.

Graduate Aeronautical Laboratories

California Institute of Technology

1200 E. California Blvd./MS 105-50

Pasadena, CA 91125

Voelkl, $\mathrm{T}$.

Graduate Aeronautical Laboratories

California Institute of Technology

1200 E. California Blvd./MS 105-50

Pasadena, CA 91125

$\mathrm{Xu}, \mathrm{L}$.

Graduate Aeronautical Laboratories

California Institute of Technology

1200 E. California Blvd./MS 105-50

Pasadena, CA 91125

Yu, C.

Graduate Aeronautical Laboratories

California Institute of Technology

1200 E. California Blvd./MS 105-50

Pasadena, CA 91125

Zikry, M. A.

North Carolina State University

Mechanical \& Aerospace Engineering

2412 Broughton Hall, Box 7910

Raleigh, NC 27695 
Zwissler, J. G.

Jet Propulsion Laboratory

4800 Oak Grove Drive - MS 97-8

Pasadena, CA 91 109-8099

Los Alamos National Laboratory

Mail Station 5000

P.O. Box 1663

Los Alamos, NM 87545

Attn: D. Cagliostro, MS F645

Attn: D. L. Crane, MS P946

Attn: J. F. Davis, MS P234

Attn: K. M. Hanson, MS P940

Attn: R. Henninger, MS D413

Attn: B. L. Holian, MS B268

Attn: K. S. Holian, MS D413

Attn: J. M. Hyman, MS B284

Attn: M. E. Jones, MS B259

Attn: J. R. Kamm, MS D413

Attn: E. J. Kelly, MS F600

Attn: J. V. Lagrange, MS D445

Attn: L. G. Margolin, MS D413

Attn: M. McKay, MS F600

Attn: M. R. Miller, MS D471

Attn: M.-M. Peterson, CIC-12

Attn: W. J. Rider, MS D413

Attn: D. Sharp, MS B213

Attn: R. N. Silver, MS B262

Attn: D. Weeks, MS B295

University of California

Lawrence Livermore National

Laboratory

7000 East Ave.

P.O. Box 808

Livermore, CA 94550

Attn: T. F. Adams, MS-L098

Attn: S. F. Ashby, MS-L561

Attn: J. Bolstad, MS-L023

Attn: D. L. Brown, MS-L561

Attn: P. N. Brown, MS-L561

Attn: R. Klein, MS-L023

Attn: S. Lee, MS-L560

Attn: C. F. MacMillan, MS-L098
Attn: C. Mailhiot, MS-L055

Attn: J. F. Mcenerney, MS-L591

Attn: D. Nikkel, MS-L342

Attn: C. K. Nitta, MS-L096

Attn: P. Raboin, MS-L125

\section{SANDIA INTERNAL}

MS 0746 D. G. Robinson, 5411

MS 1201 J. M. McGlaun, 5903

MS 1138 A. L. Hodges, 6535

MS 0778 G. Barr, 6851

MS 9403 M. Baskes, 8712

MS 9405 R. Jones, 8742

MS 9405 P. Klein, 8742

MS 9405 R. A. Regueiro, 8743

MS 9011 J. C. Meza, 8950

MS 9011 P.T. Boggs, 8950

MS 9011 M. L. Koszykowski, 8950

MS 1110 L. J. Lehoucq, 8950

MS 0841 P. Hommert, 9100

MS 0828 T. C. Bickel, 9101

MS 0841 J. A. Fernandez, 9102

MS 0828 R. K. Thomas, 9102

MS 0828 R. A. Garber, 9102

MS 0836 C. W. Peterson, 9104

MS 0835 S. N. Kempka, 9111

MS 0835 R. J. Cochran, 9111

MS 0835 D. K. Gartling, 9111

MS 0835 B. Hassan, 9111

MS 0835 W. Wolfe, 9111

MS 0834 A. C. Ratzel, 9112

MS 0826 W. Hermina, 9113

MS 0826 T. J. Bartel, 9113

MS 0836 K. S. Chen, 9114

MS 0836 L. A. Monday, 9114

MS 0836 R. R. Rao, 9114

MS 0836 P. R. Schunk, 9114

MS 0825 W. H. Rutledge, 9115

MS 0825 F. G. Blottner, 9115

MS 0825 M. McWherter-Payne, 9115

MS 0825 D. L. Potter, 9115

MS 0836 M. R. Baer, 9116

MS 0836 S. Tiezen, 9116

MS 0827 R. O. Griffith, 9117 
MS 0827 J. Johannes, 9117

MS 0835 J. S. Peery, 9121

MS 0847 S. W. Attaway, 9121

MS 0847 M. L. Blanford, 9121

MS 0847 M. W. Heinstein, 9121

MS 0847 S. W. Key, 9121

MS 0847 G. M. Reese, 9121

MS 0555 M. W. Garrett, 9122

MS 0847 H. S. Morgan, 9123

MS 0847 J. B. Aidun, 9123

MS 0847 A. F. Fossum, 9123

MS 0847 D. R. Martinez, 9124

MS 0847 K. Alvin, 9124

MS 0847 J. Dohner, 9124

MS 0557 T. J. Baca, 9125

MS 0553 R. A. May, 9126

MS 0827 J. D. Zepper, 9131

MS 0827 G. Sjaardema, 9131

MS 0827 J. R. Stewart, 9131

MS 0827 L. Taylor, 9131

MS 0828 J. Moya, 9132 (20)

MS 0828 T. Y. Chu, 9132

MS 0828 R. S. Baty, 9133

MS 0828 B. F. Blackwell, 9133

MS 0828 K. J. Dowding, 9133

MS 0828 A. R. Lopez, 9133

MS 0828 K. E. Metzinger, 9133

MS 0828 W. L. Oberkampf, 9133

MS 0828 T. Paez, 9133

MS 0828 V. J. Romero, 9133

MS 0828 C. Romero, 9133

MS 1135 D. B. Davis, 9134

MS 0321 W. J. Camp, 9200

MS 0318 G. S. Davidson, 9201

MS 0318 R. J. Pryor, 9201

MS 0316 J. E. Kelly, 9202

MS 0316 P. F. Chavez, 9204

MS 0819 T. G. Trucano, 9211 (30)

MS 1110 S. Chakerian, 9211

MS 0847 M. Eldred, 9211

MS 0847 A. A. Giunta, 9211

MS 1110 W. Hart, 9211

MS 1110 V. Leung, 9211

MS 1110 C. A. Phillips, 9211

MS 0847 J. Red-Horse, 9211
MS 1110 B. van Bloemen Waanders, 9211

MS 0318 P. Heermann, 9215

MS 1109 C. F. Diegert, 9215

MS 1111 S. S. Dosanjh, 9221

MS 1111 S. Plimpton, 9221

MS 1111 A. Salinger, 9221

MS 1111 J. N. Shadid, 9221

MS 1110 D. Womble, 9222

MS 1110 S. Istrail, 9222

MS 1110 R. Lehoucq, 9222

MS 1110 S. Minkoff, 9222

MS 1110 L. A. Romero, 9222

MS 9223 N. Pundit, 9223

MS 0321 A. L. Hale, 9224

MS 0321 J. Ang, 9224

MS 1109 R. Benner, 9224

MS 0449 G. M. Pollock, 9224

MS 1109 J. L. Tompkins, 9224

MS 1111 G. Heffelfinger, 9225

MS 1111 R. M. Fye, 9225

MS 1111 H. Hjalmarson, 9225

MS 0441 R. Leland, 9226

MS 1111 B. Hendrickson, 9226

MS 0819 E. Boucheron, 9231

MS 0819 K. Brown, 9231

MS 0819 K. G. Budge, 9231

MS 0819 D. Carroll, 9231

MS 0819 R. Drake, 9231

MS 0836 E. S. Hertel, 9116

MS 0819 A. C. Robinson, 9231

MS 0819 R. Summers, 9231

MS 0819 R. Weatherby, 9231

MS 0819 M. Wong, 9231

MS 0820 P. Yarrington, 9232

MS 0820 R. Brannon, 9232

MS 0820 D. Crawford, 9232

MS 0820 E. Fang, 9232

MS 0820 A. Farnsworth, 9232

MS 0820 M. E. Kipp, 9232

MS 0820 S. A. Silling, 9232

MS 0820 P. A. Taylor, 9232

MS 1221 J. S. Rottler, 9800

MS 0419 R. G. Easterling, 9800

MS 0829 K. V. Diegert, 12323

MS 0829 M. Abate, 12323 
MS 0829 B. M. Rutherford, 12323

MS 0638 M. A. Blackledge, 12326

MS 0638 D. E. Peercy, 12326

MS 0337 R. D. Skocypec, 15002

MS 1179 J. R. Lee, 15340

MS 0899 Technical Library,4916 (2)
MS 0612 Review and Approval Desk, 04912 (1) for DOE/OSTI

MS 9018 Central Technical Files, $8940-2$ 